\title{
On the Capability of Metal-Halogen Groups to Participate in Halogen Bonds
}

\author{
Steve Scheiner \\ Department of Chemistry and Biochemistry \\ Utah State University \\ Logan, Utah 84322-0300, United States
}

\begin{abstract}
A number of halogen $(\mathrm{X})$ atoms were covalently attached to a metal $(\mathrm{M})$ and the ability of the $\mathrm{X}$ atom to act as electron acceptor in a halogen bond to nucleophile $\mathrm{NCH}$ was assessed. Both $\mathrm{Cl}$ and $\mathrm{Br}$ were considered as halogen atom, with $\mathrm{NH}_{3}$ and $\mathrm{CO}$ as other ligands attached to the metal. Metals tested were Ti, Mn, and $\mathrm{Zn}$ in various combinations of oxidation state, coordination, and overall charge. In the majority of cases, the strong electron-releasing power of the metal imbues the halogen atom with a high negative partial charge and minimizes the development of a $\sigma$-hole. As such, the $\mathrm{M}$ atom is generally a stronger attractor for the incoming nucleophile than is the halogen. Nonetheless, there are cases where a halogen bond can form such as $\mathrm{Ti}(\mathrm{CO})_{4} \mathrm{Br}^{+}, \mathrm{TiCl}_{3}{ }^{+}$, and $\mathrm{MnCl}_{4}{ }^{+}$, each with a different coordination. A requisite of halogen bond formation is generally an overall positive charge, although neutral species can engage in such bonds, albeit much weaker.
\end{abstract}

keywords: molecular electrostatic potential; Ti; $\mathrm{Mn} ; \mathrm{Zn}$ 


\section{INTRODUCTION}

The idea that the bridging hydrogen atom of a H-bond can be replaced by any of a number of much more electronegative atoms has spawned a great deal of study in recent years. Probably the first of these noncovalent bonds to receive recognition was the halogen bond (XB) ${ }^{1-9}$ where $\mathrm{H}$ is replaced by $\mathrm{Cl}, \mathrm{Br}$, or $\mathrm{I}$ ( $\mathrm{F}$ is a reluctant participant in such bonds). The intuitive counterargument that such an electronegative atom ought to repel the nucleophilic partner was dispelled by careful study of the electron distribution around the $X$ atom. The density suffers from a certain degree of polar flattening, which in turn depletes the density in the region along the R-X covalent bond ${ }^{10-14}$. The resulting area of positive electrostatic potential has gained the sobriquet of a $\sigma$-hole, which can attract an anion or any other nucleophile. The XB is not dependent solely on this electrostatic attraction, but also benefits from polarization/charge transfer and dispersion contributions ${ }^{15-18}$.

This sort of phenomenon is not limited to halogen atoms; replacement of $\mathrm{X}$ by atoms from the chalcogen ${ }^{19-27}$, pnicogen ${ }^{28-39}$, and tetrel ${ }^{40-55}$ families of elements can lead to very similar noncovalent bonds, which are generally named after the particular type of atom, e.g. tetrel bonds. These ideas have even been extended to the aerogen, or inert gas, family of atoms, which ${ }^{56-59}$ can also develop positive regions of electrostatic potential in certain bonding situations.

In light of the above factors, the strength of a given halogen bond ought to depend in large part on the intensity of the $\sigma$-hole, i.e. the depletion of density opposite the R substituent. It follows logically that a more electron-withdrawing R group should produce a more intense $\sigma$ hole and thereby a stronger RX·Nuc halogen bond. This expectation has indeed been confirmed, not only for XBs, but for their chalcogen, pnicogen, and tetrel bond cousins as well. The greater electron withdrawal from $\mathrm{X}$ by the $\mathrm{R}$ substituent also alters the energy and spatial distribution of the $\sigma^{*}(\mathrm{RX})$ antibonding orbital which is the recipient of charge that is transferred from the nucleophile in such a way as to strengthen the XB. A second major issue is the electronegativity and polarizability of the halogen atom. As this atom is enlarged, the lower electronegativity and higher polarizability in the $\mathrm{F}<\mathrm{Cl}<\mathrm{Br}<$ I sequence is reflected in growing strength of the associated RX $\cdot$ Nuc halogen bonds. 
Halogen bonds have been found to be widespread in nature, occurring in inorganic, organic, biological, and pharmaceutical agents alike ${ }^{60-68}$. As such, there is a wide spectrum of atom or group to which the halogen is covalently attached in such bonds. The bulk of study of halogen bonds has focused on $\mathrm{C}-\mathrm{X}$ systems wherein the halogen is covalently attached to a $\mathrm{C}$ atom, which is in turn part of a larger organic system. But this has by no means been a strict limitation, as there are numerous examinations of halogens bonded to other atoms as well.

One of the more common bonding situations of a halogen atom, particularly in inorganic and crystal environments, is attached as a ligand to a metal atom. A metal atom $\mathrm{M}$ by its nature is typically electron-releasing, which would tend to amplify any partial negative charge on a halogen atom bonded to it. Not surprisingly then, halogen atoms attached to metals have been shown to be capable of acting as electron donors in XBs ${ }^{26,69-71}$. And in a converse situation, there are instances found in the literature wherein a metal atom can serve as a nucleophile in a halogen bond ${ }^{72-77}$.

But the central question under scrutiny here is whether a halogen attached to a metal atom can act as electron acceptor. The release of electrons by the metal ought to inhibit the development of any $\sigma$-hole opposite the M-X bond, which in turn would argue against the formation of a M-X $\cdots$ Nuc halogen bond. However, halogen bonds opposite electron-releasing groups are not uncommon, the methyl or other alkyl groups being prime examples. Even the electronegative $\mathrm{F}$ atom, with its low polarizability, can form halogen bonds under certain conditions, despite the absence of a $\sigma$-hole.

Given the widespread occurrence of M-X covalent bonds in nature, particularly in the realm of coordination chemistry, it seems important to probe the possibility that systems of this type might participate in halogen bonds. Which metals might be candidates for such bonds, and in combination with which halogen atoms? Are there particular oxidation states of the metals which are especially prone to engage in halogen bonds? Would such bonds be most favorable in certain coordinations or geometries surrounding the central metal atom? Does the possibility of a halogen bond vanish when the coordination complex has a particular overall charge? And in those cases where a halogen bond is feasible, how strong might it be, and what factors would control its strength? It is the goal of the present work to investigate these questions using modern quantum chemical methods. 


\section{SYSTEMS AND METHODS}

A range of different sorts of systems were examined here. As central metal atoms, Ti was chosen, along with $\mathrm{Mn}$ and $\mathrm{Zn}$. Ti was considered in both its +2 and +4 oxidation states, along with $\mathrm{Mn}^{+5}$ and $\mathrm{Zn}^{+2}$, providing a range of different electron configuration, charges, and metal types. $\mathrm{NH}_{3}$ and $\mathrm{CO}$ were both considered as neutral ligands, with varying numbers of each. Halogen atoms tested were both the commonly occurring $\mathrm{Cl}$ and its larger $\mathrm{Br}$ analogue. The differing numbers of ligands lead to a wide range of geometries, varying from linear and trigonal up to tetrahedral, pyramidal, bipyramidal, and octahedral. $\mathrm{NCH}$ was chosen as the common nucleophile which might engage in a XB with the halogen atom of the Lewis acid. Its small size and linear shape minimized complications of secondary interactions with the other ligands.

Quantum calculations were carried out via the Gaussian 09 suite of programs ${ }^{78}$. The M062X DFT functional was used in conjunction with the aug-cc-pVDZ basis set ${ }^{79,80}$. Interaction energies were computed as the difference in energy between the full complex, and its two components in the geometries they adopt within the complex, corrected for basis set superposition error by the standard counterpoise ${ }^{81}$ protocol. The properties of the bond critical

point between halogen and nucleophile were assessed via the AIMALL program ${ }^{82}$. The molecular electrostatic potential surrounding the Lewis acid molecules was illustrated via the Chemcraft program ${ }^{83}$, and maxima on the $\rho=0.001$ au isodensity surface were located and quantified by the Multiwfn program ${ }^{84}$.

\section{RESULTS}

\section{1. $\mathrm{NH}_{3}$ Ligands}

One $\mathrm{Cl}^{-}$and a varying number of neutral $\mathrm{NH}_{3}$ ligands were added to a central $\mathrm{Ti}^{+2}$ and the resulting complex fully optimized. As each $\mathrm{Ti}\left(\mathrm{NH}_{3}\right)_{\mathrm{n}} \mathrm{Cl}^{+1}$ entity bears a positive charge, it ought to attract a nucleophile, and potentially engage in a halogen bond through its $\mathrm{Cl}$ atom. The resulting structures of these monomers are illustrated in Fig 1, along with their molecular electrostatic potential (MEP). It must first be understood that the potential surrounding each of these cations is positive in all directions. The blue and red regions indicate respectively the most and least positive regions. It is immediately clear that the $\mathrm{Cl}$ atom on the right of each molecule is surrounded by a barely positive potential, indicated by the red surface. More specifically, there is no $\sigma$-hole along the extension of the $\mathrm{Ti}-\mathrm{Cl}$ covalent bond that would have signaled its presence by a blue area. And indeed, a search of the MEP on the $\rho=0.001$ au isodensity surface 
reveals no such $\sigma$-hole associated with the $\mathrm{Cl}$ atom for any of these monomers. The maxima on this surface are denoted $\mathrm{V}_{\mathrm{s}, \max }$ and their values are listed in Table 1. There are quite a number of such maxima but they can be categorized as being associated with the central Ti atom, or with some other atom or group, but not in the $\mathrm{T}-\mathrm{Cl} \sigma$-hole area.

Given the absence of a $\sigma$-hole for any of these $\mathrm{Ti}\left(\mathrm{NH}_{3}\right)_{\mathrm{n}} \mathrm{Cl}^{+1}$ monocations, it is no surprise that a base is not drawn toward the $\mathrm{Cl}$ so as to form a halogen bond. When the NCH model base was initially placed in such a position, along the extension of the Ti-Cl bond axis, it moved to other positions as the structure was optimized. As reported in the last column of Table 1, for $n=2$ and 5, the $\mathrm{NCH}$ molecule formed $\mathrm{NH}^{\cdots} \mathrm{N}$ H-bonds with the $\mathrm{NH}_{3}$ ligands. In the cases of $\mathrm{n}=3$ and 4, the $\mathrm{NCH}$ formed a Ti-N covalent bond with the Ti as an additional ligand.

\section{CO Ligands}

As an alternative to the $\mathrm{NH}_{3}$ ligand, $\mathrm{CO}$ has several advantages. In the first place, $\mathrm{CO}$ is less electron-donating, so might aid in the buildup of a positively charged region near the $\mathrm{Cl}$ so as to attract a nucleophile. As a second advantage, the lack of $\mathrm{H}$ atoms on the $\mathrm{CO}$ ligand avoids the presence of positively charged NH groups that pull the nucleophile in toward a H-bond, and thus away from the desired halogen bond.

A series of systems were thus designed with a central Ti, but with varying numbers of $\mathrm{CO}$ ligands and halogen atoms, either $\mathrm{Cl}$ or $\mathrm{Br}$. The first of these tested combines $\mathrm{Ti}^{+2}$ with $4 \mathrm{CO}$ and one $\mathrm{Cl}^{-}$, with an overall charge of +1 . The MEP around the $\mathrm{Cl}$ in Fig 2a is fully red, so does not seem to suggest a $\sigma$-hole. The most positive (bluest) areas instead lie in the vicinity of the Ti, removed from the various ligands. These indications are confirmed by the first row of Table 2 which finds the largest $\mathrm{V}_{\mathrm{s} \text {,max }}$ near the Ti atom. Its large magnitude of more than $230 \mathrm{kcal} / \mathrm{mol}$ is partly a reflection of the overall positive charge of the entire complex. Placement of a NCH base along the extension of the $\mathrm{Ti}-\mathrm{Cl}$ bond does not optimize to a halogen bond, but instead the base is pulled toward the very blue area near the $\mathrm{Ti}$ and eventually forms a covalent bond with $\mathrm{Ti}$.

Replacing the $\mathrm{Cl}$ by the less electronegative and more polarizable $\mathrm{Br}$ is known to enhance halogen bonding, and this system provides another example of this tendency. The potential around the $\mathrm{Br}$ atom in Fig $2 \mathrm{~b}$ is red, but a bit more positive than in the $\mathrm{Cl}$ analogue. Analysis of the MEP finds a maximum along the extension of the Ti-Br bond, albeit much less intense than those surrounding the Ti atom. Nonetheless, the $\sigma$-hole along the Ti-Br extension is sufficiently 
intense to generate a $\operatorname{TiBr}^{\cdot} \mathrm{N}$ halogen bond. As reported in the second row of Table 2 , the $\mathrm{R}\left(\mathrm{Br}^{*} \mathrm{~N}\right)$ distance is $3.288 \AA$ and the interaction energy is $-4.75 \mathrm{kcal} / \mathrm{mol}$. The presence of this $\mathrm{XB}$ is further confirmed by AIM analysis which finds a bond critical point with a density of $0.0084 \mathrm{au}$. As mentioned above this particular $\sigma$-hole is less intense than those surrounding the $\mathrm{Ti}$ atom. Indeed, placement of the $\mathrm{NCH}$ opposite the $\mathrm{Br}$ allows it to insinuate itself as a sixth ligand with a covalent Ti-N bond, $35 \mathrm{kcal} / \mathrm{mol}$ more stable than when engaging in a halogen bond with the $\mathrm{Br}$. Or if the optimization is begun with the $\mathrm{NCH}$ lying in a face formed by the $\mathrm{Br}$ and two of the $\mathrm{CO}$ ligands, it forms a noncovalent $\mathrm{Ti} \cdot \cdot \mathrm{N}$ bond that is more stable than the halogen bond by some $6 \mathrm{kcal} / \mathrm{mol}$.

By adding a second $\mathrm{Br}^{-}$, the resulting $\mathrm{Ti}(\mathrm{CO})_{4} \mathrm{Br}_{2}$ species has no net charge. While there does exist a maximum in the MEP along an extension of each $\mathrm{Ti}-\mathrm{Br}$ bond, $\mathrm{V}_{\mathrm{s}, \max }$ has a slightly negative value of $-8 \mathrm{kcal} / \mathrm{mol}$. There are also more intense maxima that are associated with the central $\mathrm{Ti}$ atom, as large as $+25 \mathrm{kcal} / \mathrm{mol}$. Consequently, the loss of overall positive charge removes the minimum on the potential energy surface that would correspond to a $\mathrm{XB}$. On the other hand, addition of a second halogen atom can also be effected in such a way as to increase the overall charge to +2 . However, doing so affects the region around this halogen atom less than it does in the vicinity of the central Ti. As seen in Table 2 and Fig 2, there is in fact no maximum in the MEP that corresponds to the halogen atom in either $\mathrm{Ti}(\mathrm{CO})_{4} \mathrm{Cl}_{2}{ }^{+2}$ or $\mathrm{Ti}(\mathrm{CO})_{4} \mathrm{Br}_{2}{ }^{+2}$, whereas $\mathrm{V}_{\mathrm{s} \text {, max }}$ near the Ti is boosted up to more than $230 \mathrm{kcal} / \mathrm{mol}$. Consequently, and $\mathrm{NCH}$ molecule initially placed along the extension of either $\mathrm{Ti}-\mathrm{Cl}$ or $\mathrm{Ti}-\mathrm{Br}$ swings around so as to form a covalent bond with $\mathrm{Ti}$ as a seventh ligand.

Another route might involve exchanging one of the $\mathrm{CO}$ ligands of $\mathrm{Ti}(\mathrm{CO})_{4} \mathrm{Cl}_{2}{ }^{+2}$ for a $\mathrm{Cl}^{-}$, yielding the $\mathrm{Ti}(\mathrm{CO})_{3} \mathrm{Cl}_{3}{ }^{+1}$ species. This substitution does not produce a $\sigma$-hole around any of the $\mathrm{Cl}$ ligands, but rather pulls a NCH in toward the Ti again as a seventh ligand. Another such exchange to $\mathrm{Ti}(\mathrm{CO})_{2} \mathrm{Cl}_{4}{ }^{0}$ leaves a neutral species, but one in which there is present a MEP local maximum near the $\mathrm{Cl}$, even if the value of $\mathrm{V}_{\mathrm{s}, \max }$ is slightly negative. This very weak $\sigma$-hole allows for the presence of a $\mathrm{TiCl}^{\cdots} \mathrm{N}$ configuration but the pair are very weakly bound with a slightly positive interaction energy. Replacing the four $\mathrm{Cl}$ atoms of $\mathrm{Ti}(\mathrm{CO})_{2} \mathrm{Cl}_{4}$ with $\mathrm{Br}$ changes the situation very little. Again, there is a very small $\mathrm{V}_{\mathrm{s}, \max }$ near the $\mathrm{Br}$, and the complex is barely bound at all by a Br-bond. 
In summary, the only species able to engage in a halogen bond of any strength is $\mathrm{Ti}(\mathrm{CO})_{4} \mathrm{Br}^{+1}$. It is also only this complex which contains a $\sigma$-hole that is sufficiently intense to attract a base like $\mathrm{NCH}$. The $\mathrm{Cl}$ atom of $\mathrm{Ti}(\mathrm{CO})_{4} \mathrm{Cl}^{+1}$ is too electronegative for this purpose, even if there are three such $\mathrm{Cl}$ atoms present as in $\mathrm{Ti}(\mathrm{CO})_{3} \mathrm{Cl}_{3}{ }^{+1}$. Raising the overall charge to +2 erases the halogen $\sigma$-hole in favor of a much more positive region near the central Ti which draws in the base, and eliminates the possibility of a halogen bond. On the other hand, if the overall charge is neutral, any $\sigma$-hole that might appear near the halogen is so weak that a $\mathrm{XB}$ is absent for all intents and purposes.

Since the $\mathrm{d}^{2}$ electron configuration of $\mathrm{Ti}^{+2}$ could be comparable in energy to $\mathrm{s}^{2}$, parallel calculations were also carried out for the triplet states of several of these systems. The results in the last four rows of Table 2 can be compared to the corresponding singlet data in the earlier rows. The change from singlet to triplet reduces $\mathrm{V}_{\mathrm{s}, \max }$ in the vicinity of the Ti atom of $\mathrm{Ti}(\mathrm{CO})_{4} \mathrm{Cl}^{+1}$. Even though there remains no formal $\sigma$-hole corresponding to the $\mathrm{Cl}$ atom, the $\mathrm{NCH}$ is able to find its way to this atom, forming a halogen bond with $\mathrm{R}\left(\mathrm{Cl} \cdot{ }^{*} \mathrm{~N}\right)=3.357 \AA$, and with an interaction energy of $-3.3 \mathrm{kcal} / \mathrm{mol}$. The same singlet $\rightarrow$ triplet change in the $\mathrm{Br}$ analogue eliminates the $\mathrm{Br} \sigma$-hole, while not altering that around the Ti. Nonetheless, a halogen bond is formed in the triplet as well as the singlet states. If a second $\mathrm{Br}$ is added, the triplet data is very similar to singlet, and in neither case is a halogen bond formed. Likewise, there is no substantive change introduced into the $\mathrm{Ti}(\mathrm{CO})_{4} \mathrm{Cl}_{2}{ }^{+2}$ system on going from a singlet to a triplet state.

\section{$\underline{\text { 3. } \mathrm{MCl}_{\mathrm{n}}}$}

Another window into the possibility of M-X halogen bonds can be viewed via a series of species, with both a variable number of halogen ligands and overall charge, and with an assortment of difference central metal atoms. The systems of interest were generated by starting with a metal in a given oxidation state, e.g. $\mathrm{Ti}^{+2}$. To this was added a progressively increasing number of $\mathrm{Cl}^{-}$ligands, each time decreasing the overall charge by one. Examples are provided by the topmost section of Table 3 which displays both $\mathrm{n}$ and overall charge $\mathrm{Q}$ for $\left(\mathrm{Ti}^{+2} \mathrm{Cl}_{\mathrm{n}}^{-}\right)^{\mathrm{Q}}$. For $n=2$ the charges balance and the overall charge is 0 , while a charge of -1 occurs if $n=3$, and so on.

After optimization of each such entity, the MEP was examined for its maxima, the values of which are listed as $\mathrm{V}_{\mathrm{s}, \max }$ in the succeeding columns of Table 3. The maximum along the Ti-Cl extension is equal to $-7.7 \mathrm{kcal} / \mathrm{mol}$ for neutral $\mathrm{TiCl}_{2}{ }^{0}$, much smaller than the value of +29.9 
$\mathrm{kcal} / \mathrm{mol}$ for MEP maxima that lie close to the Ti, confirming the diagram in Fig 3a. The negative value of the $\mathrm{Cl} \mathrm{V}_{\mathrm{s}, \max }$ leads to a halogen bond but a very weak one. The $\mathrm{R}\left(\mathrm{Cl}{ }^{*} \mathrm{~N}\right)$ distance is longer than $4 \AA$, and the interaction energy is positive when counterpoise corrections are introduced. The electron density at the bond critical point is quite low at $0.0011 \mathrm{au}$, also signaling a very weak interaction. The introduction of a third and fourth $\mathrm{Cl}^{-}$lends a negative value to all $\mathrm{V}_{\mathrm{s}, \max }$, both those near $\mathrm{Cl}$ and $\mathrm{Ti}$, as reported in the ensuing rows of Table 3 , and as illustrated in Figs $3 \mathrm{~b}$ and $3 \mathrm{c}$. In neither case do these negative potentials lead to formation of a $\mathrm{XB}$, even a weak one.

The likelihood of a XB can be enhanced if the overall charge is made more positive. $\mathrm{Ti}^{+4}$ was therefore substituted for $\mathrm{Ti}^{+2}$, leading to the data contained in the following rows of Table 3 . With two $\mathrm{Cl}^{-}$added to $\mathrm{Ti}^{+4}$, the complex has an overall charge of +2 , and the values of $\mathrm{V}_{\mathrm{s} \text {, max }}$ are large and positive. But $\mathrm{V}_{\mathrm{s}, \max }$ is far more positive around the central Ti than along the $\mathrm{T}-\mathrm{Cl}$ extension so any possible $\mathrm{XB}$ collapses to a covalent Ti-N bond wherein the $\mathrm{NCH}$ acts as a fourth ligand.

It might be noted that the diagram of the MEP in Fig $3 \mathrm{~d}$ seems to contradict the data in Table 3 in that the bluest (most positive) areas lie along the $\mathrm{Ti}-\mathrm{Cl}$ axis. This paradox rests on the formulation of the two sets of data. The surface used to show the MEP in Fig 3, as well as the others, is one which lies at $1.5 \mathrm{x}$ the $\mathrm{vdW}$ radius of the various atoms, a distance chosen to best represent what an approaching nucleophile will experience as it approaches the molecule. This surface extends some $1.9 \AA$ from the $\mathrm{Cl}$ along the $\mathrm{Ti}-\mathrm{Cl}$ extension, and $3.8 \AA$ from the $\mathrm{Ti}$ atom. The values of $V_{s, \max }$ are evaluated on an isodensity surface $(\rho=0.001 \mathrm{au})$ of the complex. This local maximum occurs $1.9 \AA$ from the $\mathrm{Cl}$ atom, very nearly the same as $1.5 \mathrm{x}$ its vdW radius. However, the $\mathrm{V}_{\mathrm{s}, \max }$ point associated with the Ti is only $1.4 \AA$ from the $\mathrm{Ti}$, very much closer than $1.5 \mathrm{x}$ its vdW radius. This much closer proximity, penetrating further beneath the electron cloud that shields a test point from the Ti nuclear charge, ramps up the positive value of $\mathrm{V}_{\mathrm{s}, \max }$, leading to its amplified value in Table 3. In the case of $\mathrm{TiCl}_{2}{ }^{+2}$, it is the comparative values of $\mathrm{V}_{\mathrm{s} \text {,max }}$ in Table 3 that better predict the collapse of a putative halogen bond into a Ti-N covalent bond.

Addition of a third $\mathrm{Cl}^{-}$yields the monocationic $\mathrm{TiCl}_{3}{ }^{+}$. Although the MEP diagram in Fig $3 \mathrm{e}$ suggests an enhanced positive region in the Ti-Cl $\sigma$-hole region, analysis of the $\rho=0.001 \mathrm{au}$ surface reveals no maximum. Notwithstanding the absence of a $\mathrm{V}_{\mathrm{s}, \mathrm{max}}, \mathrm{TiCl}_{3}{ }^{+}$ion does indeed engage in a halogen bond with $\mathrm{NCH}$. And indeed this bond is a fairly strong one: the interaction 
energy is nearly $8 \mathrm{kcal} / \mathrm{mol}$, supported by a short $\mathrm{R}(\mathrm{Cl} \cdot \cdot \mathrm{N})$ distance of $3.00 \AA$ and a density equal to 0.0118 at the bond critical point. So in the case of this species, the pictorial version of the MEP at $1.5 \mathrm{x}$ the vdW radius offers a better predictive tool than does the $\rho=0.001$ au isodensity surface.

Adding a fourth chloride reduces the total charge to 0 . There are maxima on the $\rho=0.001$ au isodensity surface both in the $\mathrm{TiCl} \sigma$-hole positions as well as closer to the central Ti. The values of $\mathrm{V}_{\mathrm{s}, \max }$ are larger for the latter, in contrast to the MEP diagram in Fig $3 \mathrm{f}$ which would suggest the opposite order. In any case, a halogen bond does form with $\mathrm{NCH}$, albeit a very weak one with an interaction energy of less than $1 \mathrm{kcal} / \mathrm{mol}$, and a $\mathrm{R}(\mathrm{Cl} \cdot \mathrm{N})$ distance of $3.4 \AA$. Adding more chlorides to the central species changes it into an overall anion. Although maxima occur on the surface along the $\mathrm{TiCl}$ axis, as evident in Table 3 and Figs $3 \mathrm{~g}$ and $3 \mathrm{~h}$, they are negative in sign, unable to attract a nucleophile, and no XB forms.

The +5 oxidation state of Mn provides a different sort of central metal atom. Like $\mathrm{Ti}^{+2}$ it is predicted to have a $3 \mathrm{~d}^{2}$ ground state configuration, but with a much higher total charge. With 4 , 5 , or $6 \mathrm{Cl}^{-}$added to the $\mathrm{Mn}^{+5}$, the MEPs in Fig 4a through 4c all suggest the presence of a $\mathrm{Cl} \sigma$ hole that could serve as the basis of a XB to NCH. The presence of such a hole is borne out by the search for maxima on the isodensity surface, as reported by the values of $\mathrm{V}_{\mathrm{s}, \max }$ in Table 3 . And these quantities are comparable in magnitude to those associated with the central Mn atom, despite the fact that the latter lie much closer to the pertinent atom than do the former. And indeed, both the cation and the neutral do engage in halogen bonds. The former is particularly strong, with an interaction energy of $-10 \mathrm{kcal} / \mathrm{mol}$, and with a close $\mathrm{R}(\mathrm{Cl} \cdot \cdot \mathrm{N})$ contact distance of $2.8 \AA$. This bond remains reasonably strong even for the neutral $\mathrm{MnCl}_{5}$, with an interaction energy of nearly $-3 \mathrm{kcal} / \mathrm{mol}$. The addition of a sixth $\mathrm{Cl}^{-}$, however, with its ensuing overall negative charge, and the negative value of the $\mathrm{Cl} \mathrm{V}_{\mathrm{s}, \max }$, removes the possibility of a $\mathrm{XB}$. It might be thought that the replacement of the $\mathrm{Cl}$ ligands by $\mathrm{Br}$ ought to enhance the chance to form a XB. Indeed, there is a bit of a reduction of the negative charge of the $\mathrm{Br} \sigma$-hole in $\mathrm{MnBr}_{6}{ }^{-}$ , as seen in Table 3, although this change is a minor one as witness comparison of Fig 4c with 4d. But again a XB fails to form.

As a point of contrast, the $\mathrm{d}^{10}$ configuration of $\mathrm{Zn}^{+2}$ was taken as another central metal atom. As indicated in Fig 5a through 5c, the presence of 2, 3 and $4 \mathrm{Cl}^{-}$ligands seems to enhance the strength of a $\mathrm{Cl} \sigma$-hole, at least in comparison to the remainder of each moiety. Table 3 verifies 
the presence of the corresponding $\mathrm{Cl} \mathrm{V}_{\mathrm{s} \text {,max }}$, but this quantity of course grows more negative along with the overall charge of the species. These quantities are more negative than those MEP maxima close to the $\mathrm{Zn}$ atom for $\mathrm{n}=2$ and 3, but less so for $\mathrm{n}=4$, fully verifying the trends in Fig 4. But it is only for the neutral $\mathrm{ZnCl}_{2}$ that a XB occurs, albeit a marginal one, with a positive interaction energy and with the NCH $3.7 \AA$ from the $\mathrm{Cl}$. The density at the bond critical point is only $0.003 \mathrm{au}$, consonant with a weak noncovalent bond.

It is tempting to again consider whether replacing the $\mathrm{Cl}$ ligands by heavier halogen atoms might enable an anion to engage in a halogen bond. The MEP of $\mathrm{ZnBr}_{3}{ }^{-}$and $\mathrm{ZnI}_{3}{ }^{-}$are illustrated in Fig 5d and 5e, respectively. Comparison with that of $\mathrm{ZnCl}_{3}{ }^{-}$suggests a progressively deeper $\sigma$-hole, a finding which is confirmed by the $8 \mathrm{kcal} / \mathrm{mol}$ less negative entry for $\mathrm{ZnBr}_{3}^{-}$in Table 3 , and another $9 \mathrm{kcal} / \mathrm{mol}$ increment for $\mathrm{ZnI}_{3}{ }^{-}$. Nonetheless, neither anion is able to form a XB: the overall negative charge of $\mathrm{ZnBr}_{3}{ }^{-}$repels the $\mathrm{NCH}$ molecule, while the latter rotates around to engage in a bifurcated $\mathrm{H}$-bond with two of the $\mathrm{I}$ atoms of $\mathrm{ZnI}_{3}{ }^{-}$.

As in the earlier systems detailed in Table 2 , several of the $\mathrm{Ti}^{+2}$ systems were examined in their triplet states as well. The increase of multiplicity has very little effect on either $\mathrm{TiCl}_{2}$ or $\mathrm{TiCl}_{4}{ }^{-2}$ : the former engages in a very weak halogen bond while the latter does not.

As a test as to whether relativistic effects might influence the results, the complex between $\mathrm{TiCl}_{3}{ }^{+1}$ and $\mathrm{NCH}$ was considered with a LANL2DZ effective core potential ${ }^{85}$ added to the Ti basis set. This potential was designed to incorporate mass-velocity and Darwin relativistic effects. This addition had essentially no effect on the interaction energy of the complex, changing it from -7.55 to $-7.60 \mathrm{kcal} / \mathrm{mol}$.

\section{SUMMARY AND DISCUSSION}

In general, the strong electron-releasing tendency of metal atoms makes them a highly effective competitor as an electron-accepting site as compared to a halogen atom bonded to the metal atom in question. With only few exceptions, the electrostatic potential surrounding the entire complex, of central metal surrounded by ligands, has its most positive regions at sites near the metal. In those cases where a $\sigma$-hole is present at all in the vicinity of the halogen atom, it is much less intense than the positive areas near the central metal atom. The same may be said of any $\mathrm{OH}$ or $\mathrm{NH}$ groups that occur on the ligands. The positive potentials surrounding the $\mathrm{H}$ atoms of, e.g. $\mathrm{OH}_{2}$ or $\mathrm{NH}_{3}$ ligands, are more intense than any halogen $\sigma$-hole. Consequently, an incoming base will form H-bonds with ligands such as these rather than a halogen bond. 
Another situation which mitigates against formation of a XB is the presence of a negative charge on the complex, as in $\mathrm{TiCl}_{3}{ }^{-}$or $\mathrm{MnCl}_{6}{ }^{-}$for example. This overall charge will oppose the approach of the negative end of the dipole of an approaching nucleophile.

For these reasons, the formation of a XB to a M-X linkage is unlikely under most circumstances. There were cases noted here where such a bond can form. Even though the base avoids the halogen in $\mathrm{Ti}(\mathrm{CO}){ }_{4} \mathrm{Cl}^{+}$in favor of a covalent bond with $\mathrm{Ti}$, the replacement of the $\mathrm{Cl}$ by $\mathrm{Br}$ does engender a $\mathrm{TiBr}^{\cdot} \mathrm{N}$ halogen bond of substantial strength, amounting to nearly 5 $\mathrm{kcal} / \mathrm{mol}$. Another example is the $\mathrm{TiCl}_{3}{ }^{+}$monocation which engages in an even stronger $\mathrm{TiCl} \cdot \cdot \mathrm{N}$ halogen bond of $7.5 \mathrm{kcal} / \mathrm{mol}$, eclipsed by the $10.0 \mathrm{kcal} / \mathrm{mol}$ halogen bond of $\mathrm{MnCl}_{4}{ }^{+}$. With respect to halogen bonding involving a neutral Lewis acid, the strongest of those involved $\mathrm{MnCl}_{5}$ with an interaction energy of $2.6 \mathrm{kcal} / \mathrm{mol}$.

Analysis of the electrostatic potential surrounding the putative halogen bond donor offers only moderate assistance in the prediction of the presence of a XB. For example, there is no maximum on the isodensity surface surrounding $\mathrm{TiCl}_{3}{ }^{+}$, despite the $7.5 \mathrm{kcal} / \mathrm{mol}$ interaction energy of its ultimate XB. Also, a negative value of the maximum of the potential at the $\sigma$-hole site does not necessarily rule out the appearance of a XB, as occurs for $\mathrm{TiCl}_{2}, \mathrm{ZnCl}_{2}$, or $\mathrm{Ti}(\mathrm{CO})_{2} \mathrm{Cl}_{4}$. Another issue has to do with the means of examining the electrostatic potential. A search for maxima on a given isodensity surface is not always consistent with a visual examination on a surface corresponding to vdW radii of the composite atoms: one may indicate maxima that the other does not.

Most of the results discussed here involved $\mathrm{Cl}$ as halogen atom, as this is the most frequent halogen ligand. However, there is a common consensus, verified by some of the calculations here, that halogen bonds are strengthened as this halogen atom becomes heavier; viz. $\mathrm{Cl}<\mathrm{Br}<\mathrm{I}$. Moreover, the lower electronegativity of the heavier atoms will tend to reduce the positive charge on the central $\mathrm{M}$ atom. Taking these two trends together, it may be presumed that such substitutions will enhance the observation of a halogen bond for $\mathrm{M}-\mathrm{Br}$ and even more so for $\mathrm{M}-\mathrm{I}$. Another issue has to do with the base. $\mathrm{NCH}$ was chosen as the universal base here for several reasons, including its small size and linearity that would minimize secondary interactions. However, a stronger base might be better able to engage in halogen bonds that are not observed here for $\mathrm{NCH}$. On the other hand, strengthening the base might also add to its attraction for the metal atom, so might not provide a competitive advantage to the XB. A larger and more bulky 
base, e.g. $\mathrm{NMe}_{3}$ or pyridine, might not be able to easily approach the central $\mathrm{M}$ and might thus settle for the halogen as a second choice for interaction site.

As mentioned above, negatively charged complexes repel the base too strongly to engage in a meaningful halogen bond. However, there are other factors that might mitigate this repulsion. A crystal environment might serve as a sort of cage, forcing the two species to lie in proximity to one another, thus facilitating formation of an interaction. The many other species present in a crystal or solvated environment would also create an overall polarizable dielectric effect, partially screening any electrostatic repulsions between the two species of interest. Indeed, there are works in the literature ${ }^{86-88}$ that demonstrate that such dielectric phenomena work to allow otherwise forbidden H-bonds between entities of like charge, so similar effects can be anticipated for halogen bonds as well.

\section{ACKNOWLEDGMENT}

The author is grateful to Dr. Tapas Kar for assistance with some of the computations. 


\section{REFERENCES}

1. O. Hassel, Science, 1970, 170, 497-502.

2. M. E. Wolf, B. Zhang, J. M. Turney and H. F. Schaefer, Phys. Chem. Chem. Phys., 2019, 21, 6160-6170.

3. $\quad$ N. Galland, G. Montavon, J. Y. Le Questel and J. Graton, New J. Chem., 2018, 42, 1051010517.

4. $\quad$ S. Scheiner and J. Lu, Chem. Eur. J., 2018, 24, 8167-8177.

5. E. Danelius, H. Andersson, P. Jarvoll, K. Lood, J. Gräfenstein and M. Erdélyi, Biochem., 2017, 56, 3265-3272.

6. T. L. Ellington, P. L. Reves, B. L. Simms, J. L. Wilson, D. L. Watkins, G. S. Tschumper and N. I. Hammer, ChemPhysChem., 2017, 18, 1267-1273.

7. J. P. M. Lommerse, A. J. Stone, R. Taylor and F. H. Allen, J. Am. Chem. Soc., 1996, 118, 3108-3116.

8. I. Alkorta, S. Rozas and J. Elguero, J. Phys. Chem. A, 1998, 102, 9278-9285.

9. P. L. Wash, S. Ma, U. Obst and J. Rebek, J. Am. Chem. Soc., 1999, 121, 7973-7974.

10. P. Politzer and J. S. Murray, J. Comput. Chem., 2018, 39, 464-471.

11. S. Ikuta, J. Mol. Struct. (Theochem), 1990, 205, 191-201.

12. V. R. Hathwar and T. N. G. Row, J. Phys. Chem. A, 2010, 114, 13434-13441.

13. R. Sedlak, M. H. Kolář and P. Hobza, J. Chem. Theory Comput., 2015, 11, 4727-4732.

14. F. Pirani, D. Cappelletti, S. Falcinelli, D. Cesario, F. Nunzi, L. Belpassi and F. Tarantelli, Angew. Chem. Int. Ed., 2019, 58, 4195-4199.

15. S. J. Ang, A. M. Mak and M. W. Wong, Phys. Chem. Chem. Phys., 2018, 20, 26463-26478.

16. J. Thirman, E. Engelage, S. M. Huber and M. Head-Gordon, Phys. Chem. Chem. Phys., 2018, 20, 905-915.

17. M. A. A. Ibrahim and A. A. M. Hasb, Theor. Chem. Acc., 2018, 138, 2.

18. U. Adhikari and S. Scheiner, J. Phys. Chem. A, 2012, 116, 3487-3497.

19. R. E. Rosenfield, R. Parthasarathy and J. D. Dunitz, J. Am. Chem. Soc., 1977, 99, 48604862.

20. L. Vogel, P. Wonner and S. M. Huber, Angew. Chem. Int. Ed., 2019, 58, 1880-1891.

21. K. Kříž, J. Fanfrlík and M. Lepšík, ChemPhysChem., 2018, 19, 2540-2548.

22. S. Scheiner, Faraday Disc., 2017, 203, 213-226.

23. K. Selvakumar and H. B. Singh, Chem. Sci., 2018, 9, 7027-7042.

24. V. d. P. N. Nziko and S. Scheiner, J. Phys. Chem. A, 2014, 118, 10849-10856.

25. I. Alkorta, J. Elguero and J. E. Del Bene, ChemPhysChem., 2018, 19, 1886-1894.

26. G. Sánchez-Sanz and C. Trujillo, J. Phys. Chem. A, 2018, 122, 1369-1377.

27. S. Scheiner, CrystEngComm, 2013, 15, 3119-3124.

28. W. Li, L. Spada, N. Tasinato, S. Rampino, L. Evangelisti, A. Gualandi, P. G. Cozzi, S. Melandri, V. Barone and C. Puzzarini, Angew. Chem. Int. Ed., 2018, 57, 13853-13857.

29. I. Alkorta and A. Legon, Molecules, 2018, 23, 2250.

30. W. Zierkiewicz, M. Michalczyk and S. Scheiner, Phys. Chem. Chem. Phys., 2018, 20, 8832-8841.

31. P. K. Sruthi, N. Ramanathan, S. Sarkar and K. Sundararajan, Phys. Chem. Chem. Phys., 2018, 20, 22058-22075.

32. Z. Latajka and S. Scheiner, J. Chem. Phys., 1986, 84, 341-347.

33. A. C. Legon, Phys. Chem. Chem. Phys., 2017, 19, 14884-14896.

34. K. W. Klinkhammer and P. Pyykko, Inorg. Chem., 1995, 34, 4134-4138. 
35. U. Adhikari and S. Scheiner, J. Chem. Phys., 2011, 135, 184306.

36. S. Scheiner, Chem. Phys., 2011, 387, 79-84.

37. S. Scheiner, Chem. Phys. Lett., 2011, 514, 32-35.

38. S. Scheiner and U. Adhikari, J. Phys. Chem. A, 2011, 115, 11101-11110.

39. S. Scheiner, J. Phys. Chem. A, 2011, 115, 11202-11209.

40. S. Gao, D. A. Obenchain, J. Lei, G. Feng, S. Herbers, Q. Gou and J.-U. Grabow, Phys. Chem. Chem. Phys., 2019, 21, 7016-7020.

41. E. Bartashevich, Y. Matveychuk and V. Tsirelson, Molecules, 2019, 24, 1083.

42. W. Dong, B. Niu, S. Liu, J. Cheng, S. Liu and Q. Li, ChemPhysChem., 2019, 20, 627-635.

43. V. R. Mundlapati, D. K. Sahoo, S. Bhaumik, S. Jena, A. Chandrakar and H. S. Biswal, Angew. Chem. Int. Ed., 2018, 57, 16496-16500.

44. A. Frontera and A. Bauzá, Chem. Eur. J., 2018, 24, 16582-16587.

45. D. Sethio, V. Oliveira and E. Kraka, Molecules, 2018, 23, 2763.

46. M. Esrafili and P. Mousavian, Molecules, 2018, 23, 2642.

47. C. Packianathan, P. Kandavelu and B. P. Rosen, Biochem., 2018, 57, 4083-4092.

48. S. Scheiner, Chem. Phys. Lett., 2019, 714, 61-64.

49. J. Del Bene, J. Elguero and I. Alkorta, Molecules, 2018, 23, 906.

50. S. J. Grabowski, Phys. Chem. Chem. Phys., 2017, 19, 29742-29759.

51. X. García-Llinás, A. Bauzá, S. K. Seth and A. Frontera, J. Phys. Chem. A, 2017, 121, 53715376.

52. W. Zierkiewicz, M. Michalczyk and S. Scheiner, Molecules, 2018, 23, 1416.

53. S. J. Grabowski and W. A. Sokalski, ChemPhysChem., 2017, 18, 1569-1577.

54. S. J. Grabowski, Applied Organometallic Chemistry, 2017, e3727.

55. W. Zierkiewicz, M. Michalczyk, R. Wysokiński and S. Scheiner, Molecules, 2019, 24, 376.

56. M. D. Esrafili, P. Mousavian and F. Mohammadian-Sabet, Mol. Phys., 2019, 117, 58-66.

57. M. D. Esrafili and A. Sadr-Mousavi, Chem. Phys. Lett., 2018, 698, 1-6.

58. A. Frontera and A. Bauza, Phys. Chem. Chem. Phys., 2017, 19, 30063-30068.

59. W. Zierkiewicz, M. Michalczyk and S. Scheiner, Phys. Chem. Chem. Phys., 2018, 20, 4676-4687.

60. L. Carreras, J. Benet-Buchholz, A. Franconetti, A. Frontera, P. W. N. M. van Leeuwen and A. Vidal-Ferran, Chem. Commun., 2019, 55, 2380-2383.

61. H. Wang, H. K. Bisoyi, A. M. Urbas, T. J. Bunning and Q. Li, Chem. Eur. J., 2019, 25, 1369-1378.

62. C.-Z. Liu, S. Koppireddi, H. Wang, D.-W. Zhang and Z.-T. Li, Angew. Chem. Int. Ed., 2019, 58, 226-230.

63. M. Virkki, A. Maurice, A. Forni, M. Sironi, V. Dichiarante, P.-F. Brevet, P. Metrangolo, M. Kauranen and A. Priimagi, Phys. Chem. Chem. Phys., 2018, 20, 28810-28817.

64. C. J. Massena, D. A. Decato and O. B. Berryman, Angew. Chem. Int. Ed., 2018, 57, 1610916113.

65. J. M. Guevara-Vela, D. Ochoa-Resendiz, A. Costales, R. Hernández-Lamoneda and Á. Martín Pendás, ChemPhysChem., 2018, 19, 2512-2517.

66. G. Bergamaschi, L. Lascialfari, A. Pizzi, M. I. Martinez Espinoza, N. Demitri, A. Milani, A. Gori and P. Metrangolo, Chem. Commun., 2018, 54, 10718-10721.

67. A. M. S. Riel, D. A. Decato, J. Sun, C. J. Massena, M. J. Jessop and O. B. Berryman, Chem. Sci., 2018, 9, 5828-5836.

68. J. Y. C. Lim and P. D. Beer, New J. Chem., 2018, 42, 10472-10475. 
69. G. Mínguez Espallargas, L. Brammer and P. Sherwood, Angew. Chem. Int. Ed., 2006, 45, 435-440.

70. L. Brammer, G. Mínguez Espallargas and S. Libri, CrystEngComm, 2008, 10, 1712-1727.

71. G. Mínguez Espallargas, F. Zordan, L. Arroyo Marín, H. Adams, K. Shankland, J. van de Streek and L. Brammer, Chem. Eur. J., 2009, 15, 7554-7568.

72. D. M. Ivanov, A. S. Novikov, I. V. Ananyev, Y. V. Kirina and V. Y. Kukushkin, Chem. Commun., 2016, 52, 5565-5568.

73. E. R. T. Tiekink, Coord. Chem. Rev., 2017, 345, 209-228.

74. Z. M. Bikbaeva, D. M. Ivanov, A. S. Novikov, I. V. Ananyev, N. A. Bokach and V. Y. Kukushkin, Inorg. Chem., 2017, 56, 13562-13578.

75. S. V. Baykov, U. Dabranskaya, D. M. Ivanov, A. S. Novikov and V. P. Boyarskiy, Cryst. Growth Des., 2018, 18, 5973-5980.

76. A. V. Rozhkov, M. A. Krykova, D. M. Ivanov, A. S. Novikov, A. A. Sinelshchikova, M. V. Volostnykh, M. A. Konovalov, M. S. Grigoriev, Y. G. Gorbunova and V. Y. Kukushkin, Angew. Chem. Int. Ed., 2019, 58, 4164-4168.

77. M. M. Naseer and K. Jurkschat, Chem. Commun., 2017, 53, 8122-8135.

78. M. J. Frisch, G. W. Trucks, H. B. Schlegel, G. E. Scuseria, M. A. Robb, J. R. Cheeseman, G. Scalmani, V. Barone, B. Mennucci, G. A. Petersson, H. Nakatsuji, M. Caricato, X. Li, H. P. Hratchian, A. F. Izmaylov, J. Bloino, G. Zheng, J. L. Sonnenberg, M. Hada, M. Ehara, K. Toyota, R. Fukuda, J. Hasegawa, M. Ishida, T. Nakajima, Y. Honda, O. Kitao, H. Nakai, T. Vreven, J. Montgomery, J. A., J. E. Peralta, F. Ogliaro, M. Bearpark, J. J. Heyd, E. Brothers, K. N. Kudin, V. N. Staroverov, R. Kobayashi, J. Normand, K. Raghavachari, A. Rendell, J. C. Burant, S. S. Iyengar, J. Tomasi, M. Cossi, N. Rega, J. M. Millam, M. Klene, J. E. Knox, J. B. Cross, V. Bakken, C. Adamo, J. Jaramillo, R. Gomperts, R. E. Stratmann, O. Yazyev, A. J. Austin, R. Cammi, C. Pomelli, J. W. Ochterski, R. L. Martin, K. Morokuma, V. G. Zakrzewski, G. A. Voth, P. Salvador, J. J. Dannenberg, S. Dapprich, A. D. Daniels, O. Farkas, J. B. Foresman, J. V. Ortiz, J. Cioslowski and D. J. Fox, Gaussian 09, Wallingford, CT,

79. Y. Zhao and D. G. Truhlar, Theor. Chem. Acc., 2008, 120, 215-241.

80. T. H. J. Dunning, J. Chem. Phys., 1989, 90, 1007-1023.

81. S. F. Boys and F. Bernardi, Mol. Phys., 1970, 19, 553-566.

82. T. A. Keith, AIMALL, TK Gristmill Software, Overland Park KS,

83. G. A. Zhurko, Chemcraft, http://www.Chemcraftprog.Com

84. T. Lu and F. Chen, J. Comput. Chem., 2012, 33, 580-592.

85. P. J. Hay and W. R. Wadt, J. Chem. Phys., 1985, 82, 270-283.

86. Í. Iribarren, M. M. Montero-Campillo, I. Alkorta, J. Elguero and D. Quiñonero, Phys. Chem. Chem. Phys., 2019, 21, 5796-5802.

87. Y. Yang, Z. Xu, Z. Zhang, Z. Yang, Y. Liu, J. Wang, T. Cai, S. Li, K. Chen, J. Shi and W. Zhu, J. Phys. Chem. B, 2015, 119, 11988-11997.

88. D. Lee, J. Lee and C. Seok, Phys. Chem. Chem. Phys., 2013, 15, 5844-5853. 
Table 1. Values of $\mathrm{V}_{\mathrm{s}, \max }$ for $\mathrm{Ti}\left(\mathrm{NH}_{3}\right)_{\mathrm{n}} \mathrm{Cl}^{+1}$ monocations and result of optimization after placing $\mathrm{NCH}$ in vicinity of $\mathrm{Cl}$.

\begin{tabular}{|l|l|l|l|}
\hline $\mathrm{Ti}\left(\mathrm{NH}_{3}\right)_{\mathrm{n}} \mathrm{Cl}^{+1}$ & \multicolumn{2}{|c|}{$\mathrm{V}_{\mathrm{s}, \max }, \mathrm{kcal} / \mathrm{mol}$} & result \\
\hline $\mathrm{n}$ & $\mathrm{Ti}$ & other & \\
\hline 2 & 208.3 & 138.0 & $\mathrm{NH} \cdot \mathrm{N} \mathrm{HB}$ \\
\hline 3 & 138.4 & 139.8 & $\mathrm{Ti}-\mathrm{N}$ bond \\
\hline 4 & 176.9 & 129.5 & Ti-N bond \\
\hline 5 & 123.8 & 112.7 & $\mathrm{NH} \cdot{ }^{*} \mathrm{~N} \mathrm{HB}$ \\
\hline
\end{tabular}

Table 2. Values of $\mathrm{V}_{\mathrm{s}, \max }$ for indicated species and result of optimization after placing $\mathrm{NCH}$ in vicinity of $\mathrm{Cl}$.

\begin{tabular}{|c|c|c|c|c|c|}
\hline & \multicolumn{2}{|c|}{$\mathrm{V}_{\mathrm{s}, \max }, \mathrm{kcal} / \mathrm{mol}$} & $\mathrm{R}, \AA$ & $\Delta \mathrm{E}, \mathrm{kcal} / \mathrm{mol}$ & $\rho_{\mathrm{BCP}}, \mathrm{au}$ \\
\hline singlet & $\mathrm{X}$ & $\mathrm{Ti}$ & & & \\
\hline $\mathrm{Ti}(\mathrm{CO})_{4} \mathrm{Cl}^{+1}$ & - & 235.6 & Ti-N & & \\
\hline $\mathrm{Ti}(\mathrm{CO})_{4} \mathrm{Br}^{+1}$ & 70.3 & 235.3 & 3.288 & -4.75 & 0.0084 \\
\hline $\mathrm{Ti}(\mathrm{CO})_{4} \mathrm{Br}_{2}{ }^{0}$ & -7.9 & 25.3 & $\mathrm{a}$ & & \\
\hline $\mathrm{Ti}(\mathrm{CO})_{4} \mathrm{Cl}_{2}^{+2}$ & - & 238.1 & Ti-N & & \\
\hline $\mathrm{Ti}(\mathrm{CO})_{4} \mathrm{Br}_{2}^{+2}$ & - & 231.9 & Ti-N & & \\
\hline $\mathrm{Ti}(\mathrm{CO})_{3} \mathrm{Cl}_{3}^{+1}$ & - & 136.8 & Ti-N & & \\
\hline $\mathrm{Ti}(\mathrm{CO})_{2} \mathrm{Cl}_{4}{ }^{0}$ & -4.7 & 30.7 & 3.650 & +0.11 & 0.0034 \\
\hline $\mathrm{Ti}(\mathrm{CO})_{2} \mathrm{Br}_{4}{ }^{0}$ & 0.2 & 29.5 & 3.625 & -0.10 & 0.0045 \\
\hline \multicolumn{6}{|l|}{ triplet } \\
\hline $\mathrm{Ti}(\mathrm{CO})_{4} \mathrm{Cl}^{+1}$ & - & 131.7 & 3.357 & -3.32 & 0.0062 \\
\hline $\mathrm{Ti}(\mathrm{CO})_{4} \mathrm{Br}^{+1}$ & - & 235.4 & 3.408 & -3.22 & 0.0068 \\
\hline $\mathrm{Ti}(\mathrm{CO})_{4} \mathrm{Br}_{2}{ }^{0}$ & -16.6 & 36.4 & $\mathrm{a}$ & & \\
\hline $\mathrm{Ti}(\mathrm{CO})_{4} \mathrm{Cl}_{2}^{+2}$ & - & 228.2 & Ti-N & & \\
\hline
\end{tabular}

${ }^{\text {ano minimum found }}$ 
Table 3. Values of $\mathrm{V}_{\mathrm{s}, \max }$ for $\mathrm{MCl}_{\mathrm{n}}{ }^{\mathrm{Q}}$ and result of optimization after placing $\mathrm{NCH}$ in vicinity of $\mathrm{Cl}$.

\begin{tabular}{|c|c|c|c|c|c|c|}
\hline & & \multicolumn{2}{|c|}{$\mathrm{V}_{\mathrm{s}, \max }, \mathrm{kcal} / \mathrm{mol}$} & $\mathrm{R}, \AA$ & $\Delta \mathrm{E}, \mathrm{kcal} / \mathrm{mol}$ & $\rho_{\mathrm{BCP}}, \mathrm{au}$ \\
\hline $\mathrm{n}$ & $\mathrm{Q}$ & $\mathrm{Cl}$ & $\mathrm{M}$ & & & \\
\hline \multicolumn{7}{|c|}{$\mathrm{Ti}^{+2}$} \\
\hline 2 & 0 & -7.7 & +29.9 & 4.239 & +0.29 & 0.0011 \\
\hline 3 & -1 & -87.2 & -92.1 & $\mathrm{a}$ & & \\
\hline 4 & -2 & -161.7 & -174.7 & $\mathrm{a}$ & & \\
\hline \multicolumn{7}{|c|}{ triplet } \\
\hline 2 & 0 & -0.4 & +46.2 & 4.239 & +0.42 & 0.0011 \\
\hline 4 & -2 & -160.8 & -152.1 & $\mathrm{a}$ & & \\
\hline \multicolumn{7}{|c|}{$\mathrm{Ti}^{+4}$} \\
\hline 2 & +2 & 206.5 & 467.1 & $\mathrm{~b}$ & & \\
\hline 3 & +1 & none & 333.4 & 3.003 & -7.55 & 0.0118 \\
\hline 4 & 0 & 5.5 & 22.7 & 3.405 & -0.47 & 0.0055 \\
\hline 5 & -1 & -74.7 & -84.4 & $\mathrm{a}$ & & \\
\hline 6 & -2 & -151.9 & - & $\mathrm{a}$ & & \\
\hline \multicolumn{7}{|c|}{$\mathrm{Mn}^{+5}$} \\
\hline 4 & +1 & 105.6 & 126.6 & 2.786 & -9.98 & 0.0180 \\
\hline 5 & 0 & 15.5 & 17.6 & 3.053 & -2.64 & 0.0104 \\
\hline 6 & -1 & -67.1 & - & $\mathrm{a}$ & & \\
\hline $6 \mathrm{Br}$ & -1 & -59.1 & - & $\mathrm{a}$ & & \\
\hline \multicolumn{7}{|c|}{$\mathrm{Zn}^{+2}$} \\
\hline 2 & 0 & -3.8 & 48.5 & 3.687 & +0.28 & 0.0031 \\
\hline 3 & -1 & -89.7 & -55.0 & $\mathrm{~b}$ & & \\
\hline $3 \mathrm{Br}$ & -1 & -81.6 & -53.5 & $\mathrm{a}$ & & \\
\hline $3 \mathrm{I}$ & -1 & -72.4 & -52.8 & c & & \\
\hline 4 & -2 & -161.8 & -182.8 & $a$ & & \\
\hline
\end{tabular}

${ }^{a}$ no minimum found

${ }^{\mathrm{b}}$ forms covalent M-N bond

cbifurcated $\mathrm{CH} \cdot \cdot \mathrm{I} \mathrm{H}-$ bond 


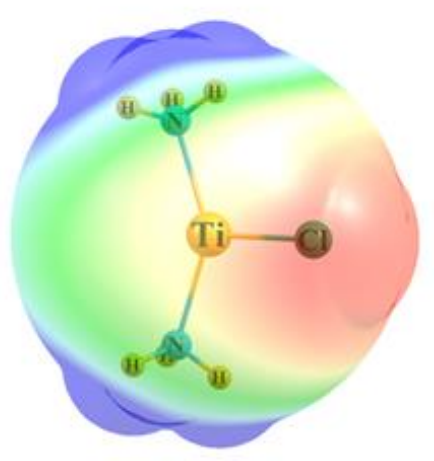

a) $n=2$

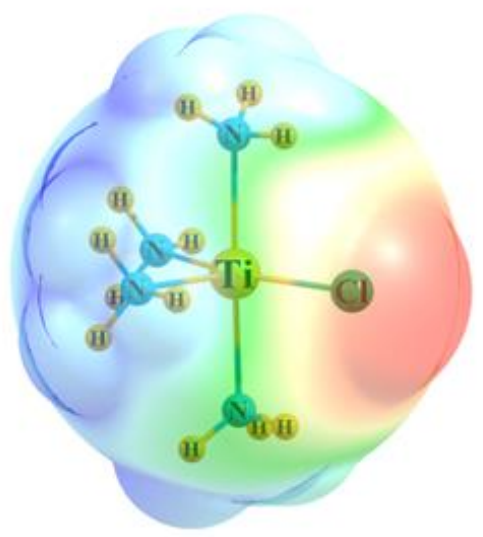

c) $n=4$

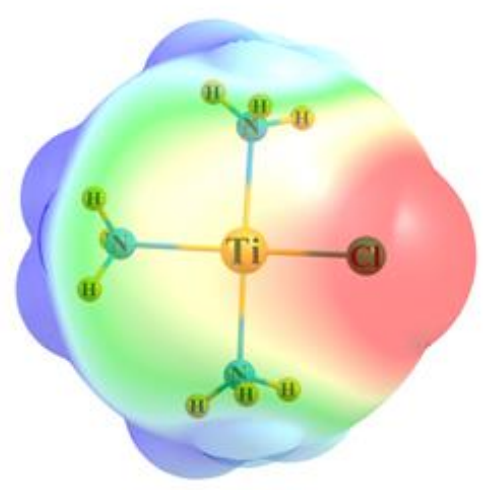

b) $n=3$

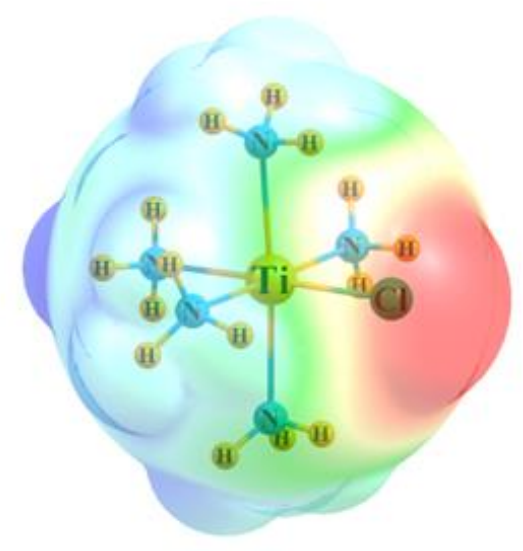

d) $n=5$

Fig 1. Molecular electrostatic potential (MEP) surrounding $\mathrm{Ti}\left(\mathrm{NH}_{3}\right)_{\mathrm{n}} \mathrm{Cl}^{+1}$. Surface corresponds to $1.5 \mathrm{x} \mathrm{vdW}$ atomic radius. Blue and red regions refer to most positive and negative regions, respectively. 


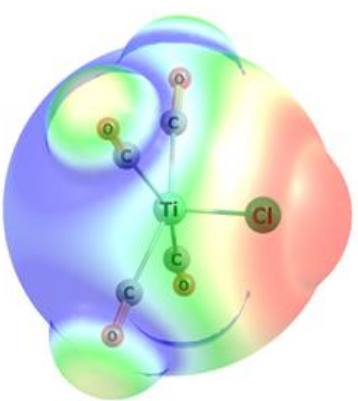

a) $\operatorname{Ti}(\mathrm{CO})_{4} \mathrm{Cl}^{+}$

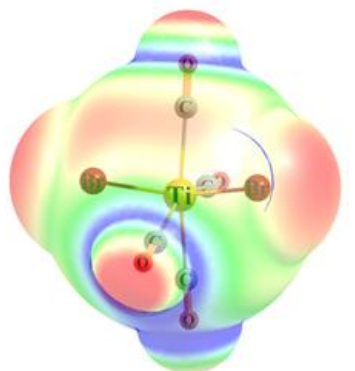

e) $\mathrm{Ti}(\mathrm{CO})_{4} \mathrm{Br}_{2}{ }^{+2}$

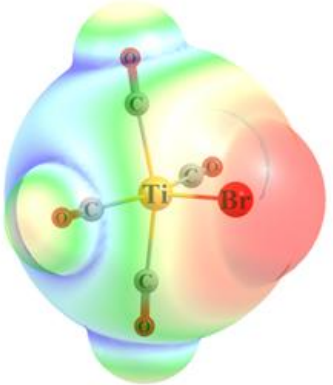

b) $\operatorname{Ti}(\mathrm{CO})_{4} \mathrm{Br}^{+}$

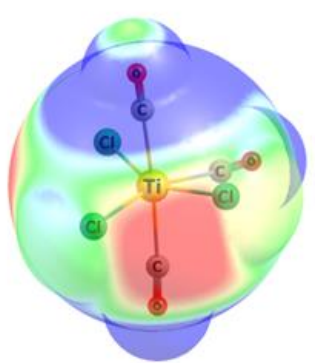

e) $\operatorname{Ti}(\mathrm{CO})_{3} \mathrm{Cl}_{3}^{+}$

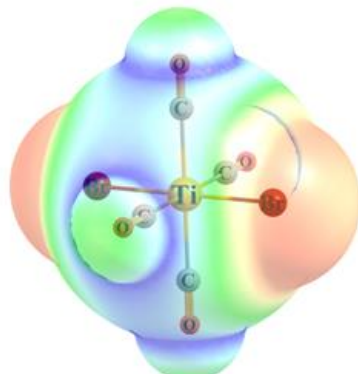

c) $\operatorname{Ti}(\mathrm{CO}){ }_{4} \mathrm{Br}_{2}{ }^{0}$

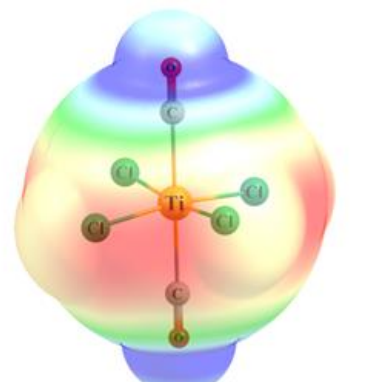

g) $\mathrm{Ti}(\mathrm{CO})_{2} \mathrm{Cl}_{4}{ }^{\mathrm{O}}$

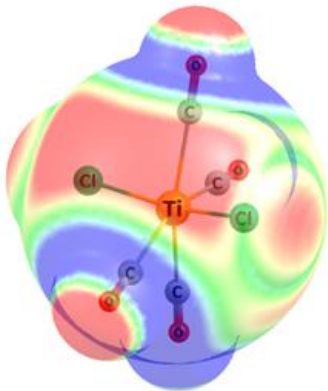

d) $\mathrm{Ti}(\mathrm{CO})_{4} \mathrm{Cl}_{2}^{+2}$

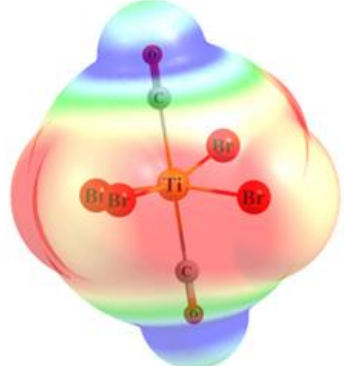

h) $\mathrm{Ti}(\mathrm{CO}){ }_{2} \mathrm{Br}_{4}{ }^{0}$

Fig 2. MEP surrounding indicated system. Blue and red regions refer to most and least positive regions, respectively. 


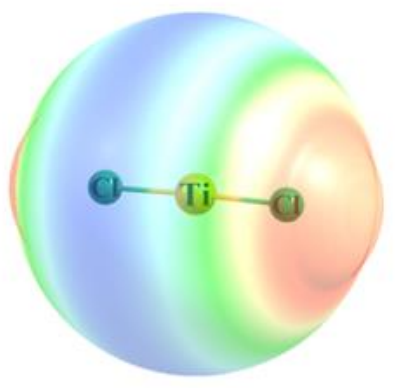

a) $\mathrm{TiCl}_{2}{ }^{0}$

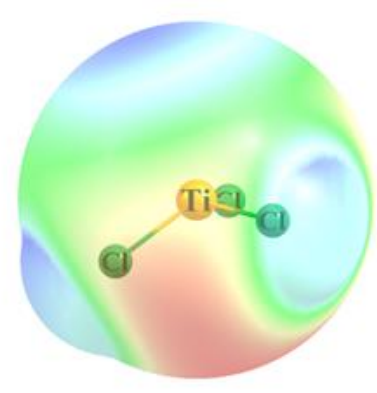

e) $\mathrm{TiCl}_{3}{ }^{+1}$

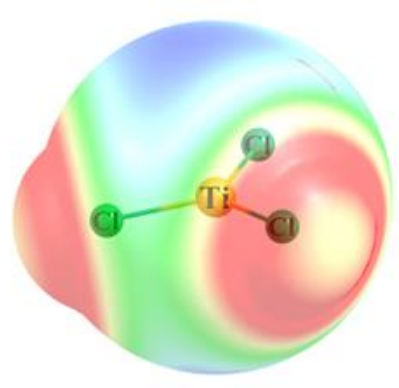

b) $\mathrm{TiCl}_{3}^{-1}$

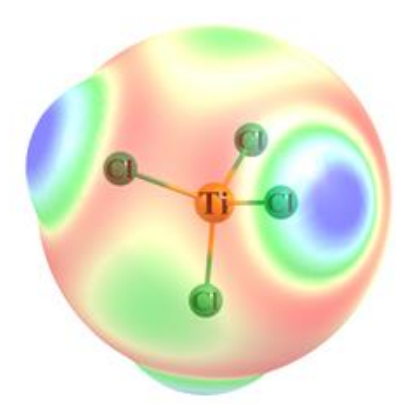

f) $\mathrm{TiCl}_{4}{ }^{0}$

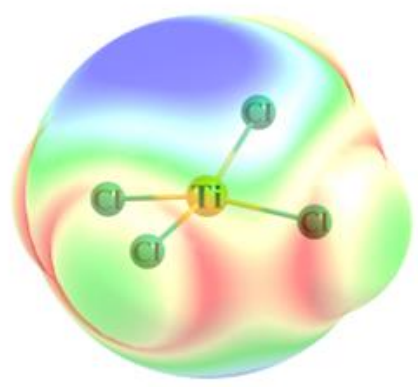

c) $\mathrm{TiCl}_{4}{ }^{-2}$

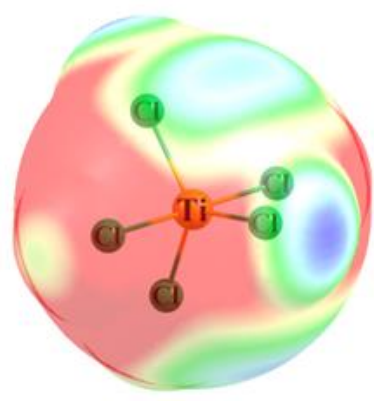

g) $\mathrm{TiCl}_{5}{ }^{-1}$

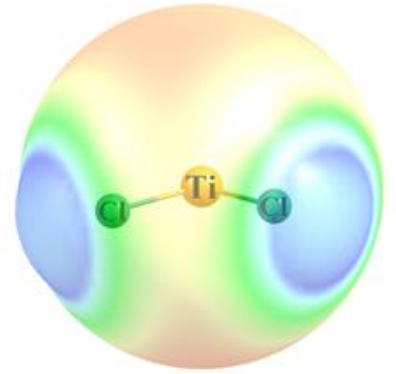

d) $\mathrm{TiCl}_{2}{ }^{+2}$

Fig 3. MEP surrounding $\mathrm{TiCl}_{\mathrm{n}}$ systems. Blue and red regions refer to most and least positive regions, respectively, or to least and most negative, depending upon overall charge. 


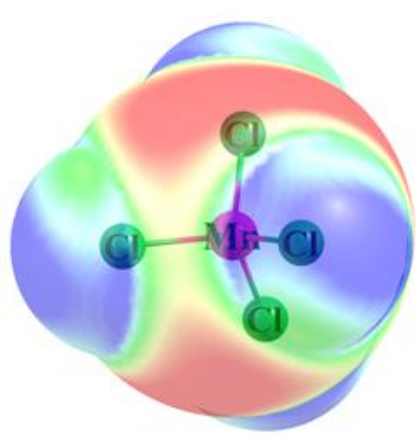

a) $\mathrm{MnCl}_{4}^{+1}$

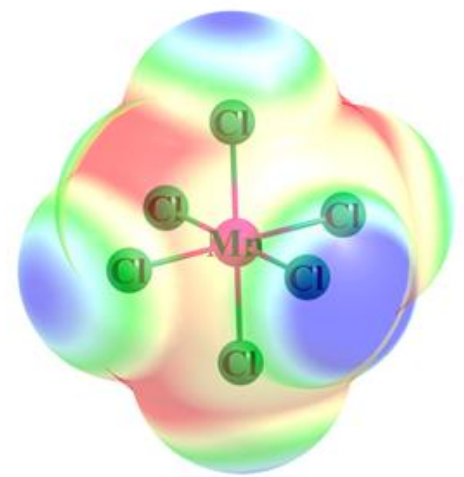

c) $\mathrm{MnCl}_{6}{ }^{-1}$

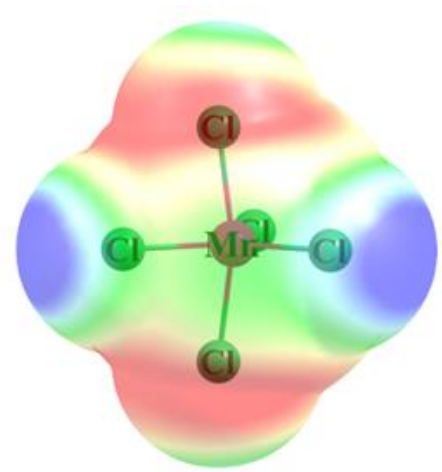

b) $\mathrm{MnCl}_{5}{ }^{0}$

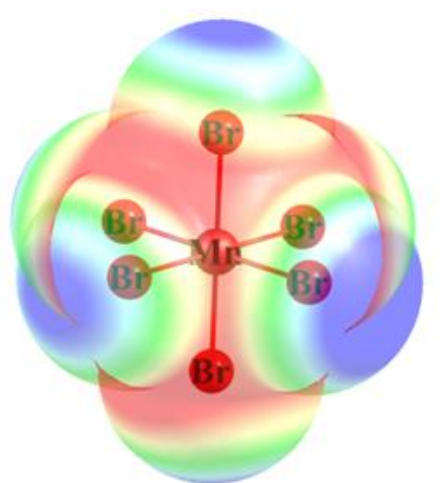

d) $\mathrm{MnBr}_{6}{ }^{-1}$

Fig 4. MEP surrounding $\mathrm{MnX}_{\mathrm{n}}$ systems. Blue and red regions refer to most and least positive regions, respectively, or to least and most negative, depending upon overall charge. 


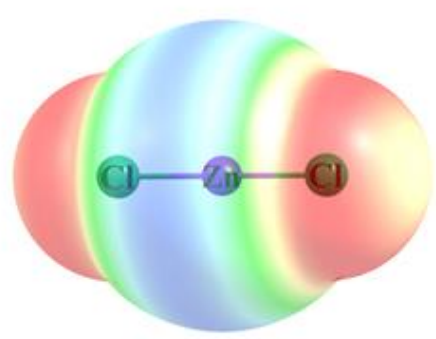

a) $\mathrm{ZnCl}_{2}{ }^{0}$

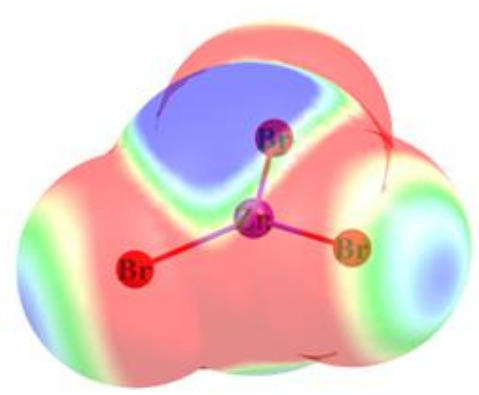

d) $\mathrm{ZnBr}_{3}{ }^{-1}$

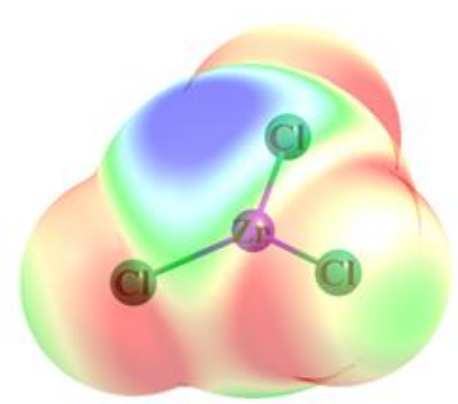

b) $\mathrm{ZnCl}_{3}{ }^{-1}$

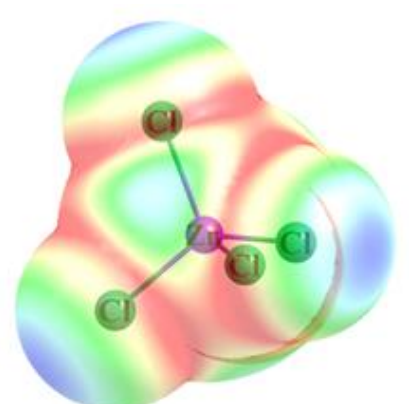

c) $\mathrm{ZnCl}_{4}{ }^{-2}$

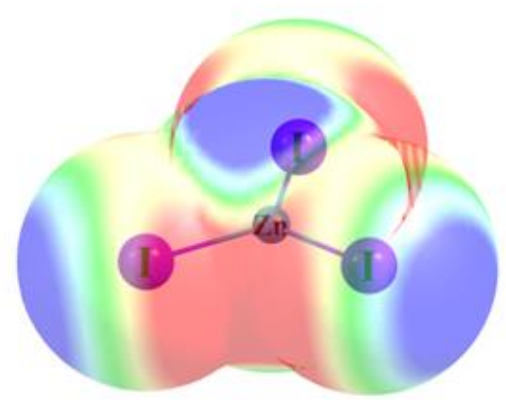

e) $\mathrm{ZnI}_{3}^{-1}$

Fig 5. MEP surrounding $Z n X_{n}$ systems. Blue and red regions refer to most and least positive regions, respectively, or to least and most negative, depending upon overall charge. 